\title{
A PMV-PPD model based study of thermal comfort in Low- Income Group house in Chhattisgarh
}

\author{
Nisha Netam $^{1, *}$, Shubhashis Sanyal ${ }^{1}$, and Shubhankar Bhowmick ${ }^{1}$ \\ ${ }^{1}$ Department of Mechanical Engineering, National Institute of Technology Raipur, Chhattisgarh, 492010, India
}

\begin{abstract}
People tend to maintain symmetry between comfort and economy while choosing essential commodities needed in their life. Families buy a house which may offer comfort condition, but at minimum in term expenses of energy throughout a life. Thus, it is most important to erect a house to provide comfortable condition and moderate the lifetime expenditure by saving energy consumption. Sensation of thermal comfort varies from people to people, even in an identical environment. To minimize the consumption of energy of building, cost of consumed energy and to provide a comfortable house, thermal comfort analysis in indoor environments have attracted many researchers. Fanger's Predicted Mean Vote (PMV) - Predicted Percentage of Dissatisfied (PPD) model is widely accepted theory for assessment of building indoor thermal conditions. In the present work, thermal comfort of an LIG house in Chhattisgarh region of India has been analyzed based on PMV-PPD method for months representing three different seasons in a year i.e. May, September and December representing summer, post monsoon and winter respectively. Cooling, heating and actual energy load of LIG house has been calculated and reported for the above mentioned months. From analysis it is concluded that inhabitants are comfortable only during the winter.
\end{abstract}

Keywords: Thermal comfort, PMV-PPD model, Cooling and heating load, Thermal sensation.

\section{Introduction}

People tend to maintain symmetry between comfort and economy while choosing essential commodities needed in their life. Families buy or construct a house which may deliver comfort; however, these comfort conditions are mostly attained at the cost of high energy consumption. Thus, it is important to construct a house to provide conducive living conditions and also reduce the lifetime expenditure by saving energy consumption. A (thermal) comfort perception varies between people to people, even in identical environment. To minimize the building energy consumption, cost of consumption and a comfortable house, thermal comfort analysis of the indoors in buildings have attracted many researchers. Fanger's Predicted Mean Vote (PMV)- Percentage of Dissatisfied (PPD) model is widely used theory for assessment of indoor thermal ambiance in buildings [1].The PMV index suggested by Fanger collects the response of inhabitants exposed to the climate spaces as per the seven-point thermal sensation scale of ASHRAE. A mean vote (MV) is estimated by calculating the mean of feeling/sensation provided by all the inhabitants at that condition. The PPD shows the percentage of the inhabitants sensing discomfort in that particular environment using the seven-point thermal sensation scale of ASHRAE $(-3$ to +3$)$ as shown in table 1 .

[2] Investigated the thermal environment and comfort related answers of occupants of Hyderabad. The survey was reported for 100 subjects, providing 3962 datasets and was analyzed for different categories of people based on: tenure, gender, age and economy. It is found that thermal reception of women and old persons were higher. Presently, two different methods for thermal comfort analysis are adopted by researchers: the rational approach and the adaptive approach reported by [3]. The former approach uses the collected data from climate chamber observations to support its theory and the latter one uses field data of people who reside in building. [4] Conducted a questionnaire survey based on the subjective responses to report thermal comfort of both the modern and traditional buildings. It is found that traditional residences in Kerala has comfortable indoors in all seasons because of its unique design, materials and unique methods adopted for construction.

[5] Reported a thermal comfort and people's behaviour inspection, in the living rooms of Kanto, Japan for hot and humid season, to report the need of indoor air circulation in the building to attain thermal comfort. [6] Reported an embodied energy analysis of mud house under the Delhi climate, and concluded that mud house has little embodied energy as compared to RCC building. Cooling/heating load and actual energy analysis has also reported for mud houses. Similar analysis has been reported for houses at different locations of the country. [7] Proposed the use of simulation tools for the building energy analysis such as Energy plus, e QUEST, TRNSYS and DOE-2.1E. 
Table 1 ASHRAE thermal sensation scale

\begin{tabular}{cc}
\hline Value & Sensation \\
\hline+3 & Hot \\
+2 & Warm \\
+1 & Slightly warm \\
0 & Neutral \\
-1 & Slightly Cool \\
-2 & Cool \\
-3 & Cold \\
\hline
\end{tabular}

Literature survey reports that thermal comfort analysis of habitats at specific locations around the world has been conducted and highlighted the need of thermal comfort analysis for different regions to re-define the building design regulations. From the review it is concluded that very little work has been reported for India. Review also points towards the scarcity of such investigations for the region of Chhattisgarh.

Although the city realizes different season throughout a year, the general year long climate is hot and dry. The present study reported for summer (May) and Post monsoon months (September) and winter (December) in the year 2016 .

\section{Methods}

\subsection{Measurement of indoor and outdoor data}

The outdoor environment data of temperature and humidity were taken from IMD metrological website. For collecting the indoor data LIG house has been chosen in Kabir Nagar, Raipur $\left(21.25^{\circ} \mathrm{N}, 81.63^{\circ} \mathrm{E}\right)$, Chhattisgarh (Fig 1). Data logger with Wi-Fi enabled humidity and temperature sensors has been used to collect the data of room air humidity and temperature at three different season of the year (Fig. 2).

\subsection{Method to calculate Indoor thermal comfort indexes}

Fanger's approach is used for thermal comfort analysis which is based on field study data; it gives realistic and actual information of thermal environment. The interior thermal comfort indexes are calculated by the model proposed by Fanger.

PMV can be calculated by the following equation [8]:

$$
\begin{aligned}
P M V= & \left(0.303 e^{-0.036 M}+0.028\right)\{(M-W)- \\
& 3.96 E^{-8} f_{c 1}\left[\left(\mathrm{t}_{c 1}+273\right)^{4}-\left(\bar{t}_{r}+273\right)^{4}\right]- \\
& \left.f_{c 1} h_{c}\left(t_{c 1}-t_{a}\right)\right]-3.05\left[5.733-0.007(M-W)-P_{a}\right]- \\
& 0.42[(\mathrm{M}-\mathrm{W})-58.15]-0.0173 M\left(5.867-P_{a}\right)- \\
& \left.0.0014 \mathrm{M}\left(34-\mathrm{t}_{a}\right)\right\}
\end{aligned}
$$

Surface temperature of clothing $\left(\mathrm{t}_{\mathrm{cl}}\right)$ :

$$
\begin{aligned}
t_{c l}= & \{35.7-0.028(M-W)\}-3.96 * 10^{-8} I_{c l} * 0.155 * \\
& f_{c 1}\left[\left(t_{c l}+273\right)^{4}-\left(t_{r}+273\right)^{4}\right]-I_{c l} * 0.155 * \\
& f_{c l} h_{c}\left(t_{c l}-t_{a}\right)
\end{aligned}
$$

Clothing factor $\left(\mathrm{f}_{\mathrm{cl}}\right)$

$$
f_{c l}=\left\{\begin{array}{cc}
1.0+0.2 I_{c l} & I_{c l}<0.5 c l o \\
1.05+0.1 I_{c l} & I_{c l}>0.5 c l o
\end{array}\right.
$$

Clothing thermal insulation $\left(\mathrm{R}_{\mathrm{cl}}\right)$ :

$$
R_{c l}=0.155 I_{c l}
$$

Convective heat transfer coefficient $\left(\mathrm{h}_{\mathrm{c}}\right)$ :

$$
h c=12.1 V^{1 / 2}
$$

PPD can be calculated by the following equation:

$$
P P D=100-95 e^{\left[-\left(0.3353 P M V^{4}+0.2179 P M V^{2}\right)\right]}
$$

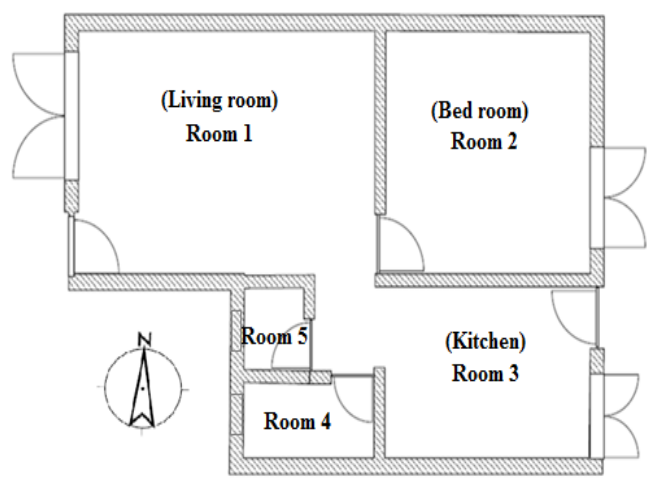

Fig. 1 LIG house plan. Living room (3.65 X3.05), bedroom (3.05 X 3.05), Kitchen (3.05 X 2.13), room 4 (2.13 X 1.21), room 5 (1.21 X 1.21). (All dimensions are in $\mathrm{m}$ )
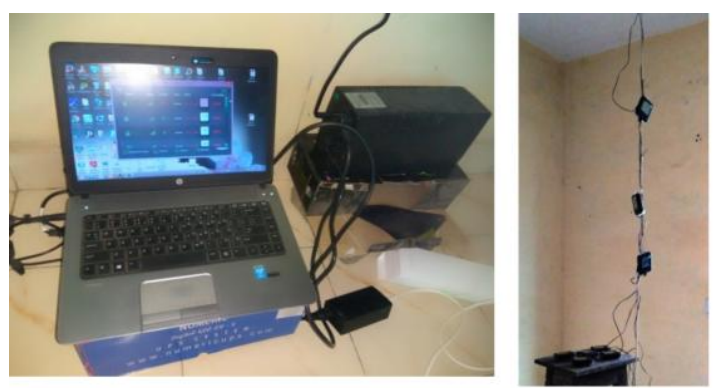

Fig. 2 Experimentation setup Data logger

\subsection{Method to calculate cooling load and actual energy}

Cooling load is the heat gain in the closed space that is needed to be removed, to maintain a steady indoor temperature. As Raipur experiences dry and hot climate mostly around the year, quantification of the annual energy use in a building, thus, requires determination of cooling loads of building. Cooling and heating load can be calculated by the determination of heat gains or heat losses of an indoor space respectively. The additional heat sources are occupants, equipment and appliances present in the house, and infiltration. 


$$
\begin{aligned}
& \text { Cooling load/ Heating load }=\mathrm{Q}_{\text {wall }}+Q_{\text {roof }}+Q_{\text {door }}+ \\
& Q_{\text {window }}+Q_{\text {inf iltration }} \\
& Q_{\text {wall,roof ,door }}=U A\left(T_{\text {sol }}-T_{0}\right) \\
& \mathrm{Q}_{\text {win }}=\left[A U\left(T_{\text {sol }}-T_{0}\right)+\mathrm{A} \tau I\right] \\
& Q_{\text {inf iltration }}=\frac{\rho V C_{a} N\left(T_{0}-T_{a m b}\right)}{3600}
\end{aligned}
$$

Where, Tsol is sol air temperature:

$$
T_{\text {sol }}=\left(\frac{\alpha I}{h_{o}}+T_{a m b}-\frac{\varepsilon \Delta R}{h_{o}}\right)
$$

For horizontal and vertical surface, $\varepsilon \Delta \mathrm{R}=60 \mathrm{~W} / \mathrm{m}^{2}$, and 0 respectively. $\mathrm{T}_{0}$ is the desired room temperature. $\left(\mathrm{T}_{0}=23^{\circ} \mathrm{C}\right)$

The actual energy load of room of LIG house is estimated from the equation proposed by [6] Actual energy load depends on the room air temperature and size of the room. Actual energy load of house:

$$
Q_{\text {Actual load }}=\left(\mathrm{M}_{\mathrm{a}} \mathrm{C}_{\mathrm{a}}\right)_{1} \mathrm{X}\left(\mathrm{T}_{\mathrm{d}}-\mathrm{T}_{\mathrm{r}}\right) \mathrm{X} \frac{1}{\left(3600 \mathrm{sh}^{-1} \mathrm{X} 1000\right)}
$$

In eq. (12) the chosen room air temperature is $T_{d}(=20$ ${ }^{\circ} \mathrm{C}$, throughout the year for the house).

\section{Results and discussion}

Thermal comfort analysis for selected LIG house has been performed for three different season winter, post monsoon and summer in the month of December, September and May, respectively. The indoor temperature and ambient temperature measured at a particular day on May 20, September 2 and December 22, is plotted in Fig. 3.

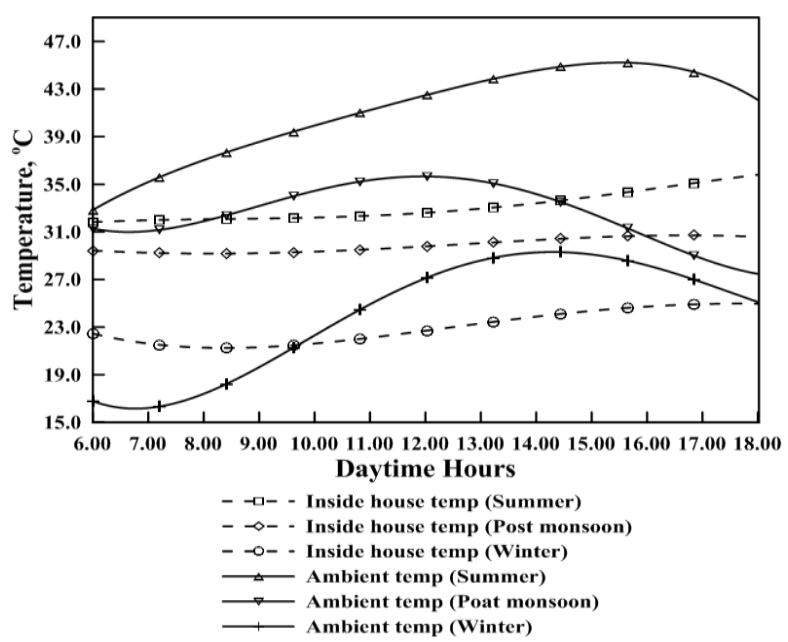

Fig. 3 Ambient temperature and indoor temperature for three different season of the year in LIG house.

\subsection{Thermal comfort at different seasons}

Using correlation proposed by Fanger's (Eq (1) and (6)) PMV and PPD calculated for the time period of 6:00 hours to 18:00 hours as shown in Figs 4 and 5. In summer indoor temperature of house throughout a day is observed above $33^{\circ} \mathrm{C}$ and calculated PMV value is greater than +3 throughout a day. Recommended thermal comfort PMV should be in the range of \pm 0.5 and $\mathrm{PPD}<10 \%$. In summer occupant feels highly uncomfortable inside the LIG house with PPD value of $100 \%$. In Post monsoon indoor temperature of house throughout a day is between $29{ }^{\circ} \mathrm{C}$ to $30.4{ }^{\circ} \mathrm{C}$ and calculated PMV value between +1.8 to +2.4 throughout a day. The occupant feels warm inside the LIG house with PPD value of nearly $100 \%$. In winter indoor temperature of house throughout a day is between $21^{\circ} \mathrm{C}$ to $24.5^{\circ} \mathrm{C}$ and calculated PMV value is between -0.06 to +1.0 throughout a day. Based on seven points thermal sensation the occupant feels neutral and slightly warm during daytime inside the LIG house with PPD value of $1.5 \%$ to $15.5 \%$.

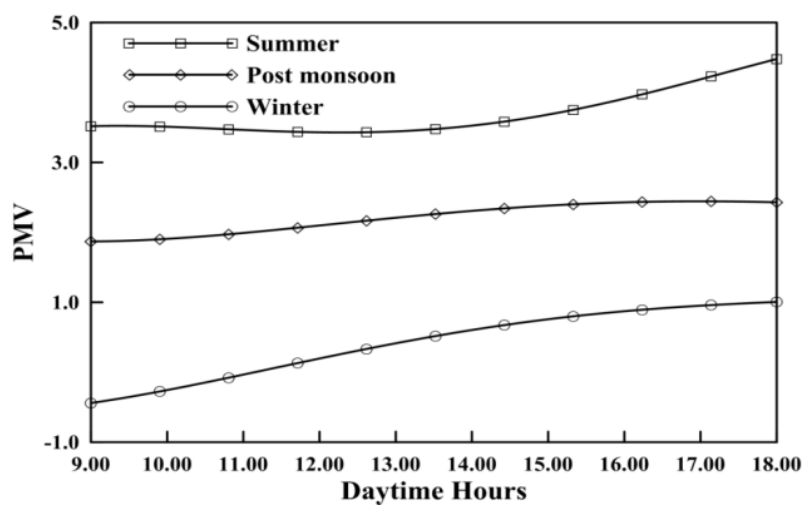

Fig. 4 Comparison on daytime PMV values for the day of three different seasons in LIG house

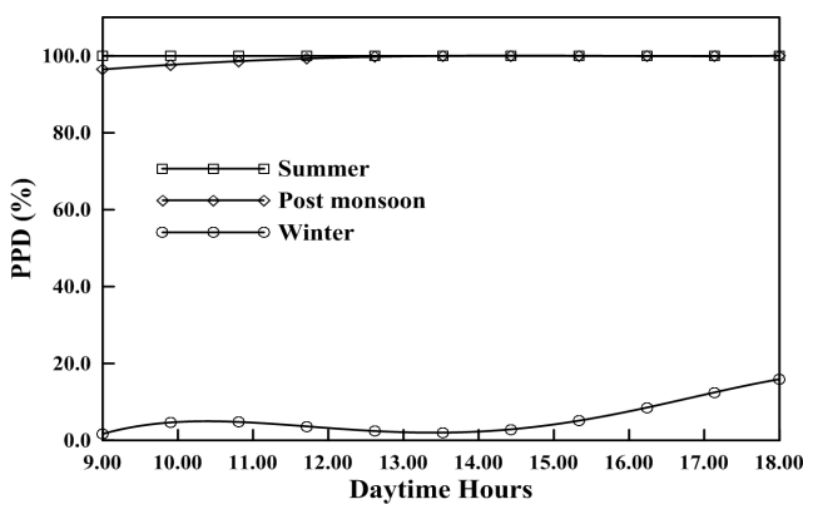

Fig. 5 Daytime PPD variation for the day of three different seasons in LIG house 


\subsection{Cooling and heating load calculation}

Cooling and heating load has been calculated for May, September and December, which are the month of three different season summer, post monsoon and winter respectively. Maximum cooling load for the month of May is $702.5 \mathrm{kWh} /$ month and followed by September is $505.5 \mathrm{kWh} /$ month. Heating load for the month of December is $169.5 \mathrm{kWh} /$ month as shown in Fig 6.

Actual energy load of each room of LIG house is calculated from the Eq. (12), hourly basis the total actual energy load of LIG house is calculated as shown in Fig. 7.

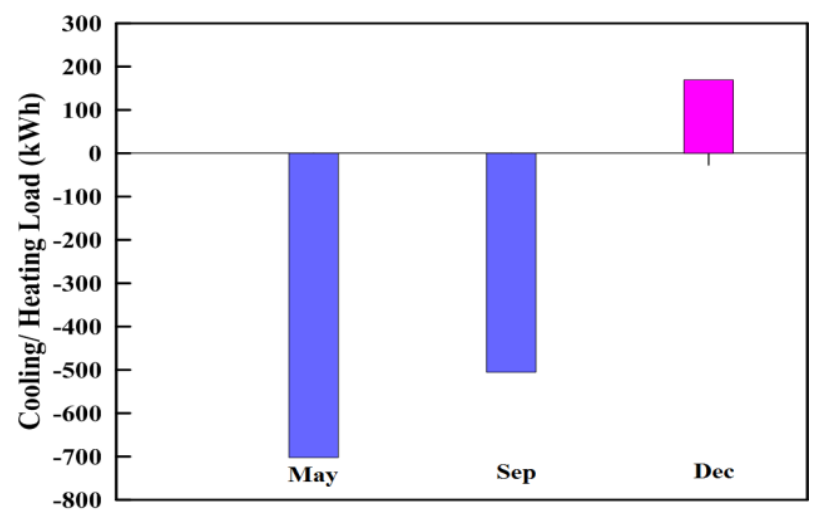

Fig. 6 Cooling and heating load analysis of LIG house.

\subsection{Cooling and heating load calculation with modification on envelope}

To study cooling/heating load of the house under different house envelope materials, house is then modelled by adding RCC roof with green roof and tiles roof. Similar comparison is performed where house is modelled by replacing burnt bricks of external wall with the brick wall with insulation material layer $(U=0.903)$ and wall made with the ECBC suggested material $(\mathrm{U}=0.440)$. Figs. 8 and 9 show the cooling/ heating load for different wall and roof materials.

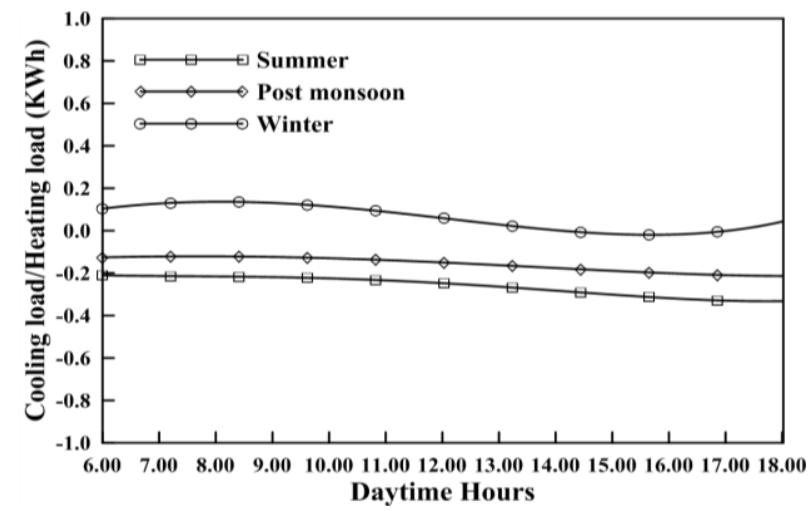

Fig. 7 Daytime actual energy load of LIG house for three different seasons.

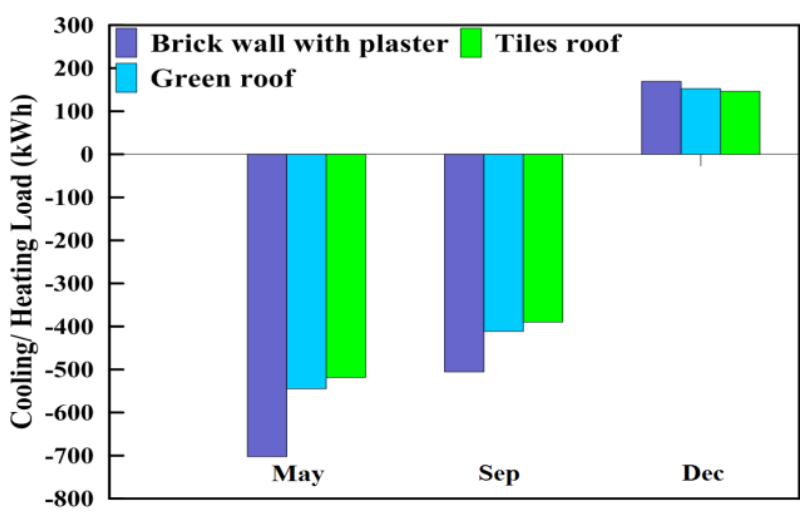

Fig. 8 Comparison of cooling and heating load analysis of LIG house for different roof materials.

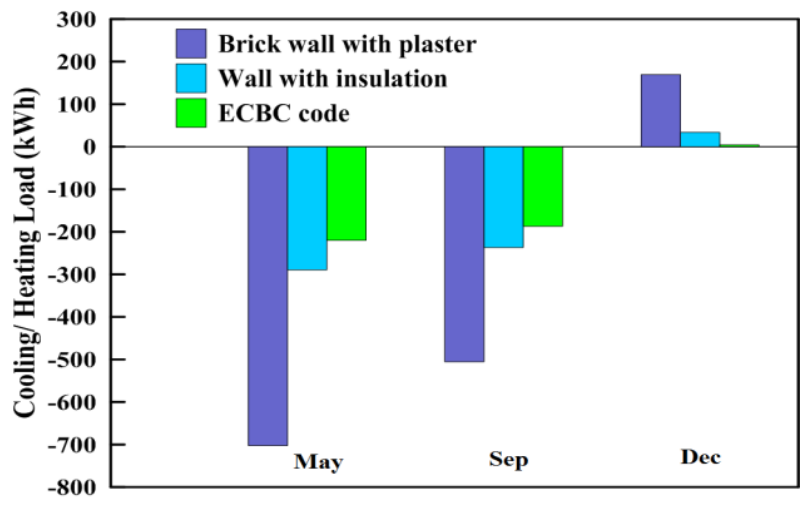

Fig. 9 Comparison of cooling and heating load analysis of LIG house for different wall materials.

\section{Conclusions}

In order to identify the comfort condition and to investigate discomfort in the LIG house at three different season of the year, data has been collected experimentally. Based on the collected data thermal comfort analysis has been investigated. The recommended PMV and PPD values are $-0.5<$ PMV $<+0.5$ and PPD $<10 \%$ for thermal comfort. Results shows that in summer, the level discomfort is very high and occupants feel the heat. During post monsoon, the occupant feels warm. In winter, the occupant feels neutral and slightly warm inside the LIG based on thermal sensation scale. Inhabitants are comfortable only during the winter season inside LIG house which remains for a period of for two months.

\section{The comfort condition of house can be improved by:}

* Replacing RCC roof of LIG house, with green roof and concrete tile roof reduced the heating/cooling load by $22.5 \%$ and $26.2 \%$ respectively.

* Replacing burnt bricks external wall, with the brick wall with insulation material layer and wall made with the ECBC suggested material 
reduced the heating/cooling load by $58 \%$ and $68 \%$ respectively.

\section{Nomenclature}

$\begin{array}{ll}\mathrm{A} & \text { Area }\left(\mathrm{m}^{2}\right) \\ \mathrm{C}_{\mathrm{a}} & \text { Specific heat of air }(\mathrm{J} / \mathrm{KgK}) \\ \mathrm{e} & \text { Euler's number }(2.718) \\ \mathrm{fcl} & \text { Clothing factor } \\ \mathrm{hc} & \text { Convective heat transfer coefficient } \\ \text { ho } & \text { Outside convective heat transfer coefficient } \\ \mathrm{I} & \text { Total solar Radiation }\left(\mathrm{W} / \mathrm{m}^{2}\right) \\ \mathrm{Icl} & \text { Clothing insulation }(\mathrm{clo}) \\ \mathrm{M} & \text { Metabolic rate }\left(\mathrm{W} / \mathrm{m}^{2}\right) 115 \text { for all scenarios } \\ \mathrm{Ma} & \text { Air mass }(\mathrm{kg}) \\ \mathrm{N} & \text { Air change rate }\left(\mathrm{h}^{-1}\right) \\ \mathrm{pa} & \text { Vapor pressure of air }[\mathrm{kPa}] \\ \mathrm{Q} & \text { Heat transfer }(\mathrm{J}) \\ \mathrm{Rcl} & \text { Clothing thermal insulation } \\ \text { ta } & \text { Air temperature }\left({ }^{\circ} \mathrm{C}\right) \\ \mathrm{tcl} & \text { Surface temperature of clothing }\left({ }^{\circ} \mathrm{C}\right) \\ \mathrm{tr} & \text { Mean radiant temperature }\left({ }^{\circ} \mathrm{C}\right) \\ \mathrm{Tr} & \text { Room temperature }(\mathrm{K}) \\ \mathrm{Ts}) & \text { Sol-air temperature }(\mathrm{K}) \\ \tau & \text { Transmissivity } \\ \mathrm{U} & \text { Overall heat transfer coefficient }\left(\mathrm{W} / \mathrm{m}^{2} \mathrm{~K}\right) \\ \mathrm{V} & \text { Air velocity }(\mathrm{m} / \mathrm{s}) \\ & \end{array}$

\section{References}

1. P.O. Fanger, Thermal Comfort-Analysis and Applications in Environmental Engineering, McGraw-Hill Book Company, New York, NY, 1972.

2. M. Indraganti, K. D. Rao Effect of age, gender, economic group and tenure on thermal comfort: A field study in residential buildings in hot and dry climate with seasonal variations. Energy and Buildings, 42(3), 273-281 (2010)..

3. N. Djongyang, , R. Tchinda, \& D. Njomo,. Thermal comfort: A review paper. Renewable and Sustainable Energy Reviews, 14(9), 2626-2640 (2010).

4. A. S. Dili, M. A. Naseer, \& T. Z. Varghese, Thermal comfort study of Kerala traditional residential buildings based on questionnaire survey among occupants of traditional and modern buildings. Energy \& Buildings, 42(11), 2139-2150 (2010).

5. H. Rijal, Investigation of Comfort Temperature and Occupant Behavior in Japanese Houses during the Hot and Humid Season. Buildings, 4(3), 437-452 (2014).

6. A. Chel, G. N. Tiwari, Thermal performance and embodied energy analysis of a passive house - Case study of vault roof mud-house in India. Applied Energy, 86(10), 1956-1969 (2009).
7. T. Ramesh, R. Prakash, \& K. K. Shukla, Life cycle energy analysis of buildings: An overview. Energy and Buildings, 42(10), 1592-1600 (2010).

8. K. Horikiri, Y. Yao, \& J. Yao, Numerical optimisation of thermal comfort improvement for indoor environment with occupants and furniture. Energy \& Buildings, 88, 303-315 (2015). 